\title{
Ciudades santuario de California: la acción política de los gobiernos locales en la política pública migratoria contemporánea de Estados Unidos
}

California's Sanctuary Cities: local government political action in contemporary United States' public policy on migration

Paola Virginia Suárez Ávila*

Resumen. Esta investigación se inserta en los estudios de antropología política acerca del fenómeno político de ciudades y estados santuario con base en el análisis de datos históricos y etnográficos que permiten entender la manera en que se han conformado las ciudades santuario desde la década de 1980 hasta nuestros días. Específicamente se analiza la ciudad y condado de San Francisco como una ciudad santuario que ha servido de modelo político y sociojurídico a otros lugares de Estados Unidos, incluso recientemente California fue declarado estado santuario. Palabras clave. Desarrollo local, gobierno local, activismo político, migración y política pública migratoria.

\begin{abstract}
This research is located within political anthropological studies regarding the political phenomenon of sanctuary cities and states, building on an analysis of historical and ethnographic data that facilitates an understanding of the way in which sanctuary cities have come into being since the 1980s until present-day. Specifically, it examines the city and county of San Francisco as a sanctuary city that has served as a political and socio-juridical model for other places in the United States, including California, which recently declared itself a sanctuary state.
\end{abstract}

Keywords. Local development, local government, political activism, migration and migratory public policy.

* Centro de Investigaciones sobre América del Norte de la Universidad Nacional Autónoma de México. 



\section{Introducción}

A través de los estudios de antropología política es posible conocer las relaciones entre el Estado y la sociedad civil, puesto que a partir de ellas se pueden analizar las interacciones de diversos actores en la práctica política y en el desarrollo de una acción política pública que beneficie a las comunidades e individuos que viven en un espacio local. Asimismo, comprender las relaciones que han tenido en el campo de la política pública migratoria distintos actores gubernamentales y no gubernamentales para desarrollar y proponer por casi treinta años, un proyecto de ley denominado Ordenanza de la Ciudad y Condado Santuario de 1989, por medio del cual se rige la autodeterminación jurídica de un condado y ciudad para otorgar refugio y protección de los derechos humanos de los inmigrantes, en respuesta a los programas y proyectos político-culturales impulsados en la sede del gobierno federal, Washington, D.C.

El campo de la política pública migratoria lo defino como el espacio donde actores de la sociedad civil y gobiernos local y federal establecen una disputa por el reconocimiento de los derechos de los inmigrantes, traducida a su vez en el reconocimiento de derechos humanos y en la posibilidad de tener una vida digna con respecto a su estatus migratorio. En adición, la propuesta de análisis político observa los cambios en la democracia contemporánea de los gobiernos locales de Estados Unidos que buscan transformar los mecanismos de la gobernanza mediante el empoderamiento y la agencia política de los inmigrantes asociados a organizaciones e instituciones, que incorporan nuevas formas de participación y deliberación dentro de sus estructuras de gobierno con el propósito de resolver un conflicto en materia migratoria.

La definición del campo de acción política migratoria parte del conflicto sociopolítico que existe en la actualidad entre los gobiernos locales de las ciudades y condados de California y el gobierno federal que preside Donald Trump, quien ha reafirmado en su campaña de acción una política antinmigrante y restrictiva en cuanto a derechos de los inmigrantes. La política neoconservadora de Donald Trump debe ser examinada como un proceso político que ha sido expuesto en debates ininterrumpidos en Estados Unidos desde los 1980 a fin de lograr la consolidación de proyectos político-culturales de carácter restrictivo respecto a la migración, justo en la década en que la migración masiva de migrantes de México y Centroamérica a Estados Unidos se convirtió en uno de los 
grandes debates en diferentes estados y se criminalizó la migración no documentada en 1996 tras la aprobación de la Ley Illegal Immigration Reform and Immigrant Responsibility Act (IIRIRA).

Paralelamente, en respuesta a este clima de poca tolerancia, deben estudiarse los esfuerzos y logros que por más de treinta años han conseguido los inmigrantes latinos no documentados en Estados Unidos, los cuales han mejorado sus condiciones de vida; además, gracias a programas como el Deferred Action for Childhood Arrivals (DACA) habían logrado - hasta el último gobierno de Obama - ser reconocidos como sujetos sociojurídicos con posibilidad de llegar al reconocimiento de ciudadanos a pesar de no existir todavía un acuerdo en torno al problema de la reforma migratoria.

El arribo de Donald Trump a la Casa Blanca ha transformado los ánimos y la política pública migratoria de las diversas comunidades de migrantes de Estados Unidos. Durante su campaña el presidente promovió el sentimiento antinmigrante y aseveró que las políticas restrictivas en carácter migratorio se aplicarían durante su mandato. En enero de 2017, ascendió al poder con una campaña nuevamente antinmigrante que avivó sus discursos de campaña y generó críticas en los distintos niveles de gobierno y en la sociedad organizada debido a los profundos cambios en la política migratoria: construcción de un muro fronterizo entre México y Estados Unidos, suspensión del Programa DACA, deportación masiva de inmigrantes no documentados, criminalización de las ciudades santuario, suspensión de programas de apoyo y asistencia a las comunidades migrantes que apoyaban las ciudades santuario.

La especificidad del caso de San Francisco es clave para analizar la manera en que se organiza una sociedad civil migrante y local. Se reconoce la importancia de los inmigrantes no documentados en la economía local y federal, así como la necesidad de los inmigrantes y refugiados de permanecer en Estados Unidos con una protección sociojurídica que les permita desarrollar sus vidas de manera digna dentro de los espacios de trabajo, comercio y vivienda en el marco de los derechos civiles y políticos que brindan gobiernos locales y la democracia liberal de Estados Unidos. Las interacciones entre sociedad civil y estados permiten conocer discursos y acción política centrados en el campo de la política migratoria. En este último subrayo la trascendencia de estados y ciudades para desarrollar su autonomía frente al gobierno de Estados Unidos con base en su propia constitución.

En adición, la acción política y el activismo dentro de las comunidades de inmigrantes establece un tipo de relaciones concretas con los gobiernos locales; 
en particular, en la ciudad de San Francisco se ha ampliado el número de actores implicados en la discusión, acción y política pública, enfocadas en los derechos de los inmigrantes en condiciones de vulnerabilidad por su estatus migratorio. Así, el estado se convierte en enlace de comunicación y de acción compleja que comprende actores gubernamentales y actores no gubernamentales, cuyas estrategias y repertorios de acción colectiva se definen en proyectos político-culturales que configuran sus recursos humanos, financieros y de acceso al poder político. Aquellos que no participan en las organizaciones civiles confían en conseguir que las comunidades no documentadas logren acceder al poder político mediante reuniones, acciones y demandas dirigidas, primeramente al gobierno local y en seguida al gobierno federal.

La presente investigación rescata los testimonios y analiza los repertorios de acción colectiva de la sociedad civil migrante de San Francisco, con fundamento en dos trabajos de campo que intentaron comprender la forma en que los inmigrantes no documentados de origen centroamericano, mexicano y asiático participan en el debate público en la ciudad y condado de San Francisco con relación al acceso a diferentes servicios: educación, salud y vivienda, asimismo pretenden contar con la ciudadanía, impulsada por la reforma migratoria.

El proceso de investigación de más diez años da cuenta de esos dos periodos de trabajo de campo, la discusión comenzó con los efectos que el 11 de septiembre de 2001 dejó en la vida cotidiana de los inmigrantes de San Francisco, al suspender las garantías constitucionales y los derechos civiles (libertad de tránsito y violación de derechos humanos, deportación, detención injustificada a miembros de la comunidad migrante no documentada y práctica del perfil racial). El proceso de recolección de datos históricos inició en 2007, un año antes de la llegada del presidente Barack Obama, que gobernó de 2009 a 2017 y con quien se trazó una forma distinta de abordar a las comunidades migrantes de las de los presidentes republicanos que le antecedieron y le suceden: George W. Bush (20012009) y el presidente en turno, Donald Trump (2017 al presente).

En el transcurso de los diez años mencionados he identificado diversos proyectos, también he conocido las propuestas y proyectos político-culturales que han amenazado la disolución de la ciudad y condado de San Francisco como ciudad santuario; de igual modo, aquellos que han reafirmado su vigencia y oportunidad en el contexto del lanzamiento de políticas antinmigrantes en el nivel federal. La etnografía del estado es una metodología propia de la antropología política contemporánea que permite descubrir el diseño de una política pública, en específico 
la Ordenanza de ciudad y condado santuario de San Francisco, con el objeto de determinar cuáles son los actores gubernamentales y no gubernamentales que promueven una política que atenta contra el gobierno federal en materia de política pública migratoria.

Sin duda, fue esencial la información de documentos en portales públicos de internet relacionados con la Ordenanza Sunshine, que obliga al gobierno local a dar a conocer las decisiones e invitaciones a reuniones públicas por distintos medios de comunicación, se eligió ésta debido a su efectividad y bajo coste para el gobierno. Varias de las organizaciones tienen la posibilidad de ser convocados y proyectar su participación con antelación en reuniones públicas, revisar minutas y continuar.

Enfatizo en las distintas acciones políticas públicas generadas en torno al nombramiento de la ciudad y condado de San Francisco como ciudad santuario a través de la ordenanza, misma que continúa vigente hasta nuestros días. Con ello pretendo destacar las actividades que ha realizado dicha ordenanza, conocida también como Ley Santuario, puesto que no han sido negativas para las comunidades locales; al contrario, han resuelto de modo oportuno el conflicto de la política pública migratoria, al mejorar la calidad de vida de los inmigrantes, considerados trabajadores y sujetos comprometidos con el desarrollo político y económico local de la región del norte de California.

\section{Las ciudades santuario en Estados Unidos}

El caso de San Francisco como ciudad y condado santuario es casi único gracias a sus contribuciones respecto a la organización social y el compromiso cívico en el estado de California y en Estados Unidos, manifestados en acervos políticos y documentos que son patrimonio para las comunidades vulnerables, incluyendo a los inmigrantes no documentados.

Tales ciudades santuario surgieron en un contexto democrático que buscaba soluciones a largo plazo para los millones de refugiados que llegaban a las ciudades de ese país con el fin de salvar sus vidas de las guerras civiles en sus países de origen ubicados en Centroamérica. Actualmente, las ciudades santuario protegen a los inmigrantes ante una posible deportación o violación de derechos humanos mediante la protección de datos y leyes a nivel local, establecidas por las ciudades y estados en materia migratoria para no cooperar con los agentes del Immigration and Customs Enforcement (ICE). 
El gobierno de California se declaró un estado santuario en colaboración y solidaridad a las más de veinte ciudades santuario que lo conforman, incluyendo a San Francisco. ${ }^{1}$ Hasta ahora su función es garantizar que las agencias de inmigración en el nivel federal no puedan obtener información y datos sobre los inmigrantes; asimismo, estipula en leyes, ordenanzas y prácticas la no cooperación de los policías con los agentes de inmigración para detener o deportar a migrantes no documentados que habitan en sus localidades (Griffith y Vaughan, 2017).

Esas prácticas han exacerbado la posición del presidente Donald Trump en cuanto a las ciudades y estados santuario, quien desde el principio de su gobierno declaró que el presupuesto federal no se aplicaría a aquellas ciudades que mantuvieran alguna práctica, ley u ordenanza de ciudad santuario; condicionó la ayuda federal y promovió la reducción de cualquier apoyo económico a las comunidades migrantes. El lado más extremo de su política fue declarar que impondría una sanción e incluso la demanda desde el gobierno federal a las ciudades santuario que no cedieran, de manera que forzó a esas entidades a eliminar el estatus como santuario con el propósito de facilitar la cooperación en materia migratoria entre el gobierno federal y los gobiernos locales.

Las amenazas a los estados que refrendan el poder de las ciudades santuario como California han suscitado la promoción de nuevos proyectos de ley, como el Senate Bill No. 54 (SB-54) que regula las relaciones de los gobiernos federal y local, lo que garantiza que aun con la ley vigente en materia de migración en el nivel federal, misma que establece que si existen razones para que una persona sea arrestada a causa de su estatus migratorio, las agencias locales deberán notificar a las agencias migratorias de Estados Unidos. En el proyecto de ley SB-54 se derogan sus disposiciones y se añaden atribuciones y regulaciones para convertirse en estado santuario. Este proyecto lo signó el 5 de octubre de 2017 el gobernador Jerry Brown, quien declara:

Este proyecto de ley, entre otras cosas y sujeto a excepciones, prohibiría que las agencias estatales y locales encargadas de hacer cumplir la ley, incluida la policía

\footnotetext{
${ }^{1}$ En el presente, las ciudades santuario en California que cuentan con alguna ley, ordenanza, resolución o práctica para proteger a los inmigrantes de la ley de Inmigración y del acceso a la información al ICE son las siguientes: Alameda County, Berkeley, Contra Costa County, Los Ángeles County, Los Ángeles, Monterey County, Napa County, Orange County, Riverside County, Sacramento County, San Diego County, San Francisco County, San Mateo County, Santa Ana, Santa Clara County, Santa Cruz County y Sonoma County. Información disponible en Griffith y Vaughan (2017).
} 
escolar y los departamentos de seguridad, usen dinero o personal para investigar, interrogar, detener, detectar o arrestar a personas con fines de ejecución migratoria, como especificado y, sujeto a las excepciones, prohibiría otras actividades o conductas relacionadas con la aplicación de leyes migratorias por parte de las agencias encargadas de hacer cumplir la ley. El proyecto de ley aplicaría esas disposiciones a las circunstancias en las que un funcionario encargado de hacer cumplir la ley tiene facultades discrecionales para cooperar con las autoridades de inmigración. El proyecto de ley exigiría, a partir del 1 de octubre de 2018, que el fiscal general, en consulta con las partes interesadas apropiadas, publique políticas modelo que limiten la asistencia con la aplicación de la ley de inmigración en la mayor medida posible para el uso de escuelas públicas, bibliotecas públicas, estado o una subdivisión política del estado, y juzgados, entre otros. ${ }^{2}$

El gobierno de California puntualiza en la regulación de la cooperación de las agencias de inmigración federales y el ICE con su propio gobierno, a fin de que esas agencias accedan a los datos de los inmigrantes con el respaldo de las agencias locales ${ }^{3}$ de California. La regulación de la información constata la diferencia de proyectos político-culturales estatales con relación al presente gobierno federal.

Según menciona Andrew R. Arthur (2017) la entidad no viola ninguna norma y ley porque se mantiene firme al Acta de los Valores de California (California Values Act) donde «se prohíbe cualquier cooperación para resolver preguntas, mantener y compartir información sobre las personas a los agentes federales de migración a menos de que ellos tengan juicios por violencia y registros criminales con agravantes». Además, después de que el Senado aprobó la ley el 16 de septiembre de 2017,

el gobernador Jerry Brown ha realizado enmiendas al proyecto de ley para mantener la cooperación con las autoridades federales de inmigración y los funcionarios de correccionales del estado y continuar ingresando a cárceles para interrogar a los inmigrantes. Por otro lado, la ley permitiría que la policía y los sheriffs compartan información y transfieran a las personas a las autoridades de migración, siempre y

2 Traducción libre de la autora. Disponible en el idioma inglés en «California Legislative Information» (2017).

${ }^{3}$ "Agencia local» refiere a cualquier ciudad, condado, ciudad y condado, distrito especial y otra subdivisión política del estado. Revisar término en «California Legislative Information» (2017). 
cuando las personas que hayan cometido más de un crimen estén determinadas en una lista de 800 descrita en una ley anterior, la California Trust Act (Arthur, 2017).

Las amenazas del gobierno de Donald Trump en contra de las ciudades santuario han suscitado declaraciones de Thomas Homan, actual director del ICE, quien argumenta que «los políticos de California han decidido priorizar la política frente a la seguridad pública». Complementariamente, el vocero del Departamento de Justicia Devin O'Malley mencionó que «los hacedores de política del estado votaron ese mismo día (el día 16 de septiembre que fue aprobada la ley en el Senado) para que regresen los extranjeros (criminal alliens) criminales a nuestras calles». ${ }^{4}$

\section{San Francisco, una ciudad santuario. Discusión vigente entre el gobierno local y la sociedad civil migrante}

El proyecto político-cultural trazado desde los líderes y los participantes activos se enfoca en el reconocimiento multicultural de que "todos son migrantes» y no le temen a las afrentas del gobierno federal. Admiten que cada caso es distinto pero comparten el tener un estatus migratorio similar, cuyo fin es la transformación en asuntos de política migratoria a pesar de que muchos de ellos no son reformistas. Examinar las coaliciones multiétnicas donde participan los miembros de la sociedad civil migrante y latina de San Francisco a fin de gestionar servicios, construir una agenda pública común y establecer comunicación con el gobierno local, implica considerar que en San Francisco hay una activa participación de la sociedad civil; además el fenómeno del asociacionismo para dar respuesta a las necesidades de los migrantes no documentados y trabajadores de baja renta que buscan mejores oportunidades de desarrollo en la ciudad de San Francisco y en la región del norte de California es permanente. Cabe mencionar que la ciudad cuenta con más de quinientas asociaciones y organizaciones que resuelven problemas y gestionan servicios a las comunidades minoritarias que habitan, laboran o estudian en el área de la Bahía de San Francisco.

El trabajo de las organizaciones (registradas o no) ha modificado las oportunidades laborales, la calidad de vida y el acceso a servicios (educación, salud y

${ }^{4}$ Ambas declaraciones citadas en el documento de Andrew R. Arthur (2017). 
vivienda) de los inmigrantes. Dos de los espacios más importantes para el desarrollo de este tipo de asociaciones y de los que corresponden a la clasificación de primera, media y segunda generaciones han sido históricamente el Chinatown y el Mission District de San Francisco. Ambos han albergado comunidades asiáticas y latinas durante el siglo XX y los albores del XXI. Son reconocidos por el gobierno local de San Francisco como distritos, de manera que tienen a un representante que comunica sus necesidades, pero sobre todo las de las comunidades de migrantes en las distintas generaciones.

La historia de cada lugar difiere, según el flujo migratorio en periodos específicos. En el siglo XX por ejemplo, se configuraron como barrios definidos por su constitución étnica y procesos de migración. En Chinatown reside una gran mayoría de migración china que hasta la fecha predomina en San Francisco, mientras que en Mission District radican mexicanos y centroamericanos, principalmente.

En contigua tesis, Chinatown se caracteriza por su activismo político desde la fundación de las primeras organizaciones a principios del siglo XX. Las restricciones de los chinos derivadas del Acta de Exclusión China de 1882, revocada hasta 1943, generó que el barrio fuera siempre un espacio de segregación y de inmigración ilegal, hecho que influyó en la poca integración de los chinos en la ciudad. Los movimientos juveniles y de derechos civiles de la región en 1968 alentaron a los asiáticoamericanos a construir nuevas organizaciones e identificar un nuevo espacio político-cultural (Chin, 2015).

Según Gordon Chin, entre 1968 y principios de la década de 1970 se gestó un movimiento sobresaliente de derechos civiles en Chinatown con la finalidad de regenerar el barrio, una vez que aumentó la población - proveniente de Hong Kong - tras la nueva ley de inmigración de 1965 que favoreció la reunificación y el asentamiento legal de las familias asiáticoamericanas, fue posible que los jóvenes participaran en la organización y la formación de nuevos liderazgos para el desarrollo de su barrio (Chin, 2015:38).

Concerniente a la historia del Mission District, la llegada de familias mexicanas a la región atravesó un proceso lento de movilización interna de mexicoamericanos y mexicanos que se desplazaron del sur al norte de California en la Segunda Guerra Mundial, en busca de oportunidades y de cambiar su realidad. En los 1960 y 1970 la población fue predominantemente mexicana y mexicoamericana, hasta muy avanzada la década de 1970 cuando comenzaron a llegar miles de refugiados provenientes de las guerras civiles en Centroamérica. 
Las organizaciones pertenecientes al área del Mission District también iniciaron su historia con este proceso de migración de los refugiados centroamericanos, con el objetivo de conseguir mejores servicios, trabajo y asesoría legal. Además, encontraron apoyo en las organizaciones ya establecidas en Los Ángeles, las cuales brindaron asesoría legal en cuanto a la existencia de leyes - como la Ley Santuario de San Francisco-, que les permitieran continuar con un proceso legal fundado en la no deportación y en una amnistía en el campo de la migración.

La consecución de la Ley Santuario fue un proceso de más de cinco años (1985-1989). Desde entonces se legitimó el derecho de los inmigrantes a circular libremente por la ciudad de San Francisco sin ser detenidos por agentes de migración. No debe olvidarse la prohibición de las agencias locales para cooperar con los agentes migratorios en el proceso de detención y obtención de datos personales, tampoco el hecho de que el gobierno local restringió los recursos materiales, económicos y humanos para la búsqueda de inmigrantes ilegales. A pesar de las críticas que ha sufrido la ley de parte de los gobiernos local y federal por obstruir la justicia y no cooperar con los programas que fortalecen la seguridad nacional, el gobierno de San Francisco mantiene su nombramiento de ciudad y condado santuario, ello ha hecho atractivo el espacio para que organizadores y activistas en favor de los derechos de los inmigrantes continúen brindando ayuda a las comunidades migrantes cercanas del área de la Bahía.

Mission District es sede de diversas organizaciones y coaliciones que luchan por los derechos de los inmigrantes en el nivel local, estatal y nacional: Centro Legal La Raza, Mujeres Unidas y Activas, People Organizing to Demand Environmental \& Economic Rights (PODER), Central American Resource Center, Causa Justa, San Francisco Immigrant Legal \& Education Network y Dolores Street Community Services, las cuales proporcionan asesoría legal, instruyen para el trabajo, enseñan inglés como segunda lengua y otorgan otros servicios relacionados con la educación y la salud en colaboración con distintas asociaciones de la región (African Advocacy Network, Arab Resource and Organizing Center, Asian American Advancing Justice, Asian Law Caucus, Asian Pacific Islander and Legal Outreach, Chinese for Afirmative Action y Filipino Community Center).

Aun cuando varios de los esfuerzos se concentran en la adquisición de educación y salud pública, las redes y las organizaciones como San Francisco 
Immigrant Legal \& Education Network (SFILEN) anticipan su trabajo en el logro de políticas públicas justas en materia migratoria y apoyo a la comunidad migrante cuando se encuentra en nuevos escenarios políticos que desafían la inmigración. Por ejemplo, SFILEN anunció el 6 de septiembre de 2017 que frente a la disposición del presidente Donald Trump de suspender el programa DACA — que daba la oportunidad a más de 800 mil jóvenes que llegaron siendo niños a Estados Unidos de lograr una residencia durante más de dos años y acceder a mejores condiciones laborales y de educación superior, mientras se lograba la reforma migratoria-, «ellos junto con otras organizaciones y abogados, se levantarían para defender los derechos humanos y la dignidad de aquellos que contarán con el DACA y de los 11 millones de migrantes no documentados que hay en todo el país». Urgieron que cualquiera que estuviera en una situación posible de deportación alertara a la línea de emergencia que se indica en el mismo documento con la finalidad de que fueran protegidos por las organizaciones locales (SFILEN, 2017).

Esta suspensión refleja la visión del presidente en cuanto a su preferencia por políticas migratorias de carácter restrictivo, aunado a la nueva incertidumbre en el futuro de los jóvenes inmigrantes. El programa DACA se consideró como el inicio de una plataforma política y legal que permitiera convertir a los inmigrantes en sujetos cívicos y jurídicos reconocidos por el Estado aun cuando no contaran con la ciudadanía. De acuerdo con el Migration Policy Institute (2017), durante los cinco años que funcionó el programa (desde 2012) es posible observar la mejora de calidad de vida y en los ingresos económicos de los jóvenes.

Donald Trump insiste en que ese programa es anticonstitucional y viola la autonomía de los gobiernos locales por ser una acción ejecutiva firmada por el expresidente Obama. Ante el escenario de nuevas políticas restrictivas que no logran el avance hacia una negociación que permita una reforma migratoria y el progreso de programas como DACA, los inmigrantes de la Bahía de San Francisco aceleran la reorganización de sus asociaciones y redes en un afán por comenzar un trabajo local y exigir de nueva cuenta que se respete la Ley Santuario.

Asimismo, se solicita que se apoye a los más de 800 mil jóvenes que quedaron sin el programa DACA en el país y que los regresa a la informalidad e ilegalidad que plantea el sistema migratorio de Estados Unidos. En San Francisco habitan alrededor de 300 mil inmigrantes que serían afectados por tales políticas (SFILEN, 2017). El alcalde de San Francisco, Ed Leede, ha expresado su rechazo y se ha aliado con alcaldes de otras ciudades como Nueva York para demandar al 
presidente, garantizar los derechos de los inmigrantes y proteger las ciudades santuario. Referente a la afirmación de Donald Trump de suspender los fondos de apoyo para las ciudades santuario, el alcalde aseveró que «si Trump está realmente interesado en hacer America seguro, entonces es imperativo que la nueva administración y el Congreso pase la Reforma Migratoria Integral» (Madhani, 2017). Hasta la fecha, la reforma migratoria de los 1990 no ha sido aprobada y las políticas en materia migratoria del gobierno federal de Estados Unidos en sus últimas administraciones se ha restringido a la inmigración, y a la manera de controlarla y criminalizarla en aras de mejorar la seguridad nacional. En ese sentido, existen tres tipos de políticas migratorias: liberales, de carácter restrictivo y de bienestar social.

La primera aborda la democracia liberal de Estados Unidos en un momento clave de la crisis económica del sistema bancario en la Gran Depresión de 1929, que otorgó una nueva coerción al sistema liberal y expandió nuevas formas de asociación que pugnaran por una mayor justicia, igualdad social y económica frente a los errores del capitalismo. El liberalismo en Estados Unidos confía en la posibilidad de aplicar un derecho positivo en favor de la sociedad a la vez que constriñe la visión negativa de la concepción de los derechos de los individuos. En adición, priorizó los valores de la democracia que promovían dicha igualdad y justicia social, justificó que la falta de restricción del capitalismo había creado un ambiente de crisis económica y de desigualdad durante 1929 (Crotty, 2016). Las comunidades vulnerables como los inmigrantes se convertirían en parte de la sociedad si sus valores coincidían con los de la democracia liberal de Estados Unidos en años posteriores.

Las políticas restrictivas han sido un modelo para organizar y criminalizar la migración en Estados Unidos, la Unión Europea y México. La problemática de la migración internacional no documentada masiva a partir de la década de 1980, ha alertado a estos países, los cuales han dirigido sus energías en la construcción de sistemas, programas y prácticas que controlen los flujos migratorios en las fronteras y en los territorios que comprenden a los Estados nación. Derivado de las políticas de restricción de la migración se han cometido abusos y violación en materia de derechos humanos. De modo que los países han tenido que justificar sus acciones ante organismos internacionales como la Organización de la Naciones Unidas (ONU) sobre prácticas y leyes que promueven la violación de derechos humanos en contra de inmigrantes. Estados Unidos se ha mostrado renuente a la vigilancia de los organismos internacionales de derechos humanos, debido a 
que sustenta sus prácticas y políticas de restricción migratoria en la vigilancia de su soberanía como Estado y en su aceptación de pelear contra el terrorismo.

Las políticas del bienestar social son aquellas que intentan mejorar la calidad de vida de sus habitantes, con base en el uso que el gobierno hace de los recursos públicos hacia las poblaciones que contribuyen a la economía. Organizaciones y centros legales vigilan que estas acciones se lleven a cabo. A lo largo de más de treinta años, el tópico de la reforma migratoria ha sido fundamental en la política estadounidense. Se abordan diversas propuestas y proyectos político-culturales, el objetivo primordial es su predominio y hegemonía en las decisiones del gobierno federal, mismo que controla el sistema migratorio a escala nacional. La Ley IRIIRA (1996) promueve distintas secciones prácticas inconstitucionales que violan los derechos humanos, en especial, la sección 287 (g), que destaca la cooperación de los agentes locales con los de migración. Dicha sección ha generado ciertas prácticas como la detención y la deportación conforme a un perfil racial, que expresan la xenofobia y el racismo de un sistema federal de migración en contra de grupos étnicos bien definidos: mexicanos, centroamericanos, asiáticos y los procedentes de las islas del Pacífico.

Si bien el gobierno federal ha desarrollado una serie de políticas restrictivas, en San Francisco continúa vigente la Ley Santuario, la cual en un principio brindó refugio a los exiliados de las guerras civiles de Centroamérica; no obstante, a partir del siglo XXI ha servido para asilar y dar refugio a los migrantes que han huido y emigrado de sus países por violencia, pobreza y desigualdad que propiciaron la apertura al libre comercio con Estados Unidos tras la firma del Tratado de Libre Comercio de América del Norte (TLCAN).

La desigualdad económica en Norteamérica ha sido poco analizada por los grupos neoconservadores de Estados Unidos que en las recientes negociaciones pretenden terminar con el TLCAN. A lo largo de más de veinte años ha negociado la entrada ilegal de mexicanos y centroamericanos con el propósito de conseguir mano de obra barata por medio de una supuesta regularización de su sistema migratorio. La movilidad y migración mexicana y centroamericana ha fortalecido la economía estadounidense, en particular la agroindustria en estados como California, que dependen básicamente de la mano de obra de los inmigrantes, quienes reciben un salario más bajo que el mínimo establecido por la ley y que está determinado por un proceso de economía informal a escala global de la no documentación de los inmigrantes que los vuelve vulnerables frente al sistema migratorio y de justicia de Estados Unidos. 
Las leyes santuario identifican las deficiencias de un sistema económico que no protege en la región a las miles e incluso millones de personas que se ven obligadas a abandonar sus hogares con la expectativa de que sus condiciones de vida sean más óptimas, que les permitan mantener un patrimonio, aunque sea lejos de su lugar de trabajo. El transnacionalismo aquí realiza sus principales aportaciones en el análisis para esclarecer los mecanismos de movilidad que hacen que los migrantes cambien su residencia y busquen una oportunidad en Estados Unidos, aun con los riesgos y debilidades del sistema migratorio.

Es importante la Ley Santuario de San Francisco porque atiende a una población de 300 mil personas que ha encontrado un espacio de seguridad para su desarrollo. Sin embargo, ha sido atacada por los grupos más conservadores de Estados Unidos; de manera que todos los días las agencias que promueven los derechos humanos (Comisión de Derechos Humanos y Comisión de Derechos de los Inmigrantes de San Francisco) deben refrendar los de los inmigrantes para no ser deportados en la ciudad. Año tras año es más difícil mantener vigente tales leyes en medio de discursos neoconservadores lanzados por el gobierno federal y que confrontan continuamente a la ciudad de San Francisco por mantener una política de refugio y de ciudad santuario para migrantes ilegales. Quizá los años más difíciles de las ciudades santuario estén por venir; no obstante, las experiencias pasadas han enseñado a los inmigrantes a organizarse, hacer llegar sus demandas y concentrarlas en torno a la Ley Santuario de San Francisco. La ley en sí se convierte en un patrimonio legal y sociojurídico para los inmigrantes en Estados Unidos que pelean por sus derechos humanos.

Desde la caída de las Torres Gemelas, el 11 de septiembre de 2001, el entonces presidente George W. Bush inició una estrategia de seguridad nacional que afectó la ley de inmigración y que dotó de nuevos poderes al gobierno federal en su lucha en contra del terrorismo. Se implementaron nuevos programas como Comunidades Seguras (S-Comm) aún vigentes pese a las críticas y la polémica por carecer de mecanismos efectivos de comprobación legal sobre su efectividad que permiten mejorar la seguridad nacional. Los gobiernos locales fueron forzados a entrar en una nueva era de cooperación con el gobierno federal con la finalidad de solucionar el problema de seguridad nacional. En los programas que se configuraron bajo esta retórica se resaltó que la defensa del territorio estadounidense no sólo debía centrarse en la frontera entre México y Estados Unidos, sino que debía enfocarse en una estrategia que comprendiera a todas las entidades políticas de Estados Unidos. 
Los nuevos programas como Comunidades Seguras ${ }^{5}$ pretendieron establecer la cooperación entre agentes locales de las distintas entidades políticas de Estados Unidos con el gobierno federal y el sistema de migración. Así, suponían que sería más fácil controlar las actividades de inmigrantes y mantener actualizados sus registros de criminalidad. Se apoyaba también la posibilidad de remoción de aquellos individuos que representaran un peligro para la nación. Lo cierto es que a pocos años de su existencia se denunció en foros comunitarios y en informes publicados por Amnistía Internacional de Estados Unidos que ésta no era la acción primera a la que respondía el programa, sino que era usado para criminalizar a los inmigrantes y registrarlos en el sistema de migración aun cuando las faltas que cometían eran administrativas, por ejemplo, no portar documentos o una licencia de manejo. El fin último del programa era justificar la deportación masiva privilegiada por prácticas que atentaban contra los derechos humanos, como lo es la detención y la deportación a causa del perfil racial (Amnesty International USA, 2004).

Desde la campaña electoral de Barack Obama a finales de 2007, la movilización de los inmigrantes en San Francisco se encauzó en denunciar las redadas, la detención y la deportación registrada en algunas localidades, principalmente en el Mission District donde habita y trabaja la mayor parte de la población indocumentada latina de la ciudad; por tanto, iniciaron discusiones que giraban en torno a la violación de derechos humanos y de la ley santuario. Una vez comenzado su primer año de gobierno, la urgencia por resolver el problema en el nivel local llevó a la Comisión de Derechos Humanos y la Comisión de Derechos de los Inmigrantes de San Francisco a organizar reuniones donde se brindaran testimonios sobre lo que acontecía en las calles de la ciudad. Las reuniones fueron impulsadas por centros legales a favor de los derechos de los inmigrantes y por otras organizaciones que los defendían, las cuales observaron el incremento de redadas y detenciones injustificadas en las calles del Mission District.

La ampliación de las redadas en las calles de San Francisco puso en alerta a la ciudad y dejó claro que iniciaba un proceso nuevo de cooperación del gobierno local con las agencias de inmigración. La mayoría de las detenciones reportadas fueron en las calles, ejercidas en contra de peatones y conductores que cumplían con rasgos fenotípicos de origen latino, de modo que la detención coincidía con el perfil de un

${ }^{5}$ Comunidades Seguras es un programa federal implementado por el ICE que se ha convertido en un tema de controversia en el país. Para más información véase Ávila, 2016. 
grupo racial determinado o bien con características socioeconómicas, enfocados a grupos latinos y de la comunidad asiáticoamericana.

El diálogo iniciado en 2009 con las agencias locales que promueven los derechos humanos y de los migrantes, sirvió para establecer una plataforma de defensa de la ciudad y condado santuario de San Francisco. Además, alentó la denuncia de los inmigrantes a través de organizaciones y centros legales que atendían sus demandas con la intención de condenar las acciones del gobierno federal y la acción de agentes de la policía que cedían a la presión del ICE para notificar sobre los detenidos y su estatus legal. El objetivo principal de estas reuniones fue revisar los efectos de la política migratoria del ICE.

La reunión convocada en los primeros días de febrero de 2009 por la Comisión de Derechos Humanos y la Comisión de Derechos de los Inmigrantes de San Francisco en colaboración con el Asian Law Caucus sobre el tema, acercó a comisionados y supervisores de los distintos distritos de San Francisco a la problemática que se vivía en la Bahía. Más tarde, se convocaría a una segunda reunión, The Impacts of Immigration Enforcement on San Francisco, donde los miembros, organizaciones e individuos de las comunidades de migrantes rindieron testimonio a las Comisiones para que se construyera una agenda en conjunto que lograra la consolidación de una agenda destinada a la ciudad de San Francisco en materia de política pública migratoria. Dicha reunión se realizó el 13 de abril de 2009. Ahí se analizaron y escucharon los testimonios de más de cuarenta individuos y organizaciones que brindaron nueva información a las Comisiones. De igual forma, se abordaron las deficiencias de algunos programas (por ejemplo, Comunidades Seguras), los efectos de la sección 287 (g) y sistemas como E-Verify, que pretendían comprobar la identidad de los trabajadores inmigrantes en sus empleos.

A todas las organizaciones civiles se hizo extensiva la convocatoria, participaron los miembros de las Comisiones y los supervisores de los distritos 9 y 11, que se relacionan con el Mission District. Gracias a los testimonios de las distintas comunidades - mexicana, centroamericana y asiática — se formó una agenda local con las demandas de los inmigrantes: poner fin a la detención fundada en el perfil racial en los aeropuertos; defender el matrimonio gay para que los inmigrantes, cuya pareja sea residente o ciudadana, accedan a los derechos que otorga esta unión; pelear por el presupuesto de las asociaciones que luchan por los derechos de los inmigrantes; frenar las redadas del ICE, en especial en el Mission District y en los centros donde prestan servicios los jornaleros; reformar la Ley 
Santuario de San Francisco; exigir una justa reforma migratoria en los niveles local, estatal y federal; otorgar identificaciones y licencias a los inmigrantes; proteger a los inmigrantes contra despidos y desalojos de vivienda masivos; eliminar la discriminación por lenguaje; proteger el derecho a residir legalmente en California. Se trataron también las acciones y el poder del gobierno local frente a los nuevos programas implementados por el ICE. Con ello comenzó en los años siguientes una discusión acerca de la vigencia de las leyes santuario en la región de la Bahía de San Francisco presentes hasta hoy.

\section{Conclusiones}

El gobierno de San Francisco ha logrado mantener el estatus de ciudad y condado santuario desde 1989, gracias a la sociedad civil migrante y al gobierno local que han denunciado las prácticas no constitucionales y aquellas que han violado derechos humanos de los inmigrantes, ejercidas por parte de agentes de migración en la ciudad. Las Comisiones de Derechos Humanos y de los Derechos de los Inmigrantes, junto con las organizaciones y centros legales en pro de los derechos de los inmigrantes, han conseguido reducir la acción de los agentes de policía locales, quienes en múltiples ocasiones se ven forzados a participar en redadas y en detenciones no justificadas de inmigrantes. La tarea del gobierno local se complica más cuando existen amenazas del gobierno federal por limitar recursos y apoyos a los gobiernos que respaldan las leyes santuario de los inmigrantes.

En la actualidad, el gobierno de San Francisco, al igual que el estado de California, informó al gobierno federal su negativa a colaborar en estas acciones impuestas por el sistema de migración. De la misma manera, el sistema de justicia del gobierno federal también afecta la permanencia de los inmigrantes no documentados en las diferentes ciudades de California y convierte en factible la deportación como un proceso de remoción.

Cabe destacar que la agenda de la sociedad civil migrante de San Francisco en materia de política pública en el nivel federal todavía se encuentra en discusión debido al arribo del nuevo presidente y a las nuevas problemáticas que deben enfrentarse. Se requiere que centros legales y organizaciones en pro de los derechos humanos y de los inmigrantes que trabajan a escala local inicien otra vez discusiones para resolver el conflicto de la reforma migratoria. Los avances 
en la agenda local en cuanto al proceso migratorio abren una posibilidad de diálogo entre sociedad civil migrante y gobierno local para soportar los embates de políticas públicas restrictivas. Asimismo, ponen en tela de juicio el hecho de que los gobiernos locales de California desarrollen políticas y leyes de ciudades santuario con la autonomía que indica la constitución de Estados Unidos.

En concreto, la cooperación entre los gobiernos local y federal debe garantizar soluciones que incidan de modo positivo en las comunidades de inmigrantes sin la violación de sus derechos humanos y bajo la vigilancia de diversas instituciones (Comisiones de Derechos Humanos y de los Derechos de los Inmigrantes) para que promuevan el ejercicio cotidiano de respeto hacia ellas. El empoderamiento de las comunidades migrantes reunidas y estructuradas en torno a organizaciones y centros legales que pugnan por la equidad y la justicia social de las minorías y los grupos vulnerables, es cada día más necesario en la sociedad estadounidense cuando se ven limitados los derechos de residencia, acceso a servicios (educación pública, salud y justicia), en un ambiente que criminaliza a los inmigrantes por no portar con documentos que acrediten su residencia y permanencia en Estados Unidos. La criminalización de la inmigración debe ser denunciada como un proceso de política pública que ha traído consecuencias importantes a las familias: deportación, separación, aumento de prácticas racistas y xenófobas en el contexto de una democracia liberal.

La sociedad civil migrante y la sociedad civil local de San Francisco han dado muestras de su organización para enfrentar los cambios en la política pública migratoria en el reciente año, tras la llegada del presidente Donald Trump. Su urgencia demuestra la presión que han ejercido sobre los gobiernos locales a fin de asegurar que la continuidad de los proyectos y programas les brinden mejores servicios y oportunidades para su desarrollo en los lugares de migración como trabajadores y comunidad migrante.

\section{Referencias}

Amnesty International (2004), Threat and humiliation. Racial profiling, domestic security and Human Rights, Nueva York, Amnesty International USA Publications.

Arthur, Andrew R. (2017), "Why is Trump losing the Sanctuary Battle?», Center of Immigration Studies, en https://cis.org/Arthur/Why-Trump-Losing-Sanctuary -Battle 
California Legislative Information (2017), «SB-54 Law enforcement: sharing data», en https://leginfo.legislature.ca.gov/faces/billNavClient.xhtmlebill_id=201720180 SB54

Chin, Gordon (2015), Building community, Chinatown style. A half century of leadership in San Francisco Chinatown, San Francisco, Chinatown Community Development Center, p. 38.

Coleman, Mathew (2007), "A geopolitics of engagement: neoliberalism, the war on terrorism, and the reconfiguration of US Immigration Enforcement», en Geopolitics, 12(4), pp. 607-634.

Crotty, William (2015), Polarized politics. The impacts of divisiveness in the US Political System, Boulder, Lynne Rienner Publishers.

De Leon, Richard E. (1988), The progressive urban regime: ethnic coalitions in San Francisco, San Francisco, Public Research Institute-San Francisco State University.

Fox, Jonathan y William Gois (2010), "La sociedad civil migrante: diez tesis para el debate», Migración y Desarrollo, 7(15), pp. 81-128.

Fung, Archon (2001), «Deepening democracy: innovations in empowered participatory governance», Politics and Society, 29(1), pp. 5-41.

Griffith, Bryan y Jessica Vaughan (2017), «Maps: Sanctuary cities, counties, and States», Center for Immigration Studies, en https://cis.org/Map-Sanctuary-Cities -Counties-and-States

Madhani, Aamer (31 de enero de 2017), «San Francisco sues Trump over Sanctuary city order», USA Today, en https://www.usatoday.com/story/news/2017/01/31/sanfrancisco -sues-trump-over-sanctuary-city-order/97291804/

SF Human Rights Commission (1989), «San Francisco City Administrative Code $12 \mathrm{H}$. Sanctuary city ordinance», en http://sf-hrc.org/Modules/ShowDocument. aspx? documentid $=766$

SFILEN (2017), «Statement of the San Francisco Immigrant Legal \& Education (SFILEN) on Deferred Action for Childhood Arrivals (DACA)», en http://sfilen.org/blog/ statement-of-the-san-francisco-immigrant-legal-education-network-sfilen-ondeferred-action-for-childhood-arrivals-daca/

Suárez Ávila, Paola (2016), "Comunidades Seguras (S-Comm): un balance sobre la política pública migratoria y el fenómeno de la deportación en la primera administración de Barack Obama (2008-2012)», en Elaine Lavine et al. (eds.), Nuevas experiencias de la migración de retorno, México, CISAN. 